\title{
The covert influence of the tobacco industry on research and publication: a call to arms
}

The tobacco industry has an ignoble history of putting its commercial interests before the interests of humanity. Its values contrast with those of the ideal medical scientist who seeks to investigate objectively the causes of disease, and methods of prevention and treatment, for the benefit of the health of humanity. The pervasive and often covert influence of the tobacco industry on scientific research and publication has undermined this ideal and poses ethical challenges for research institutions, researchers and journal editors.

Commercial sponsorship of scientific research is common. The issues raised here are likely to apply more widely, so why have we singled out the tobacco industry? The tobacco companies produce an addictive product that is highly dangerous at all intensities of use, and that kills prematurely up to half of its lifelong users. ${ }^{1}$ The industry is still actively seeking new markets around the world. The main tobacco companies continue to question the overwhelming evidence showing tobacco is addictive and harmful to human health, and have tried to influence the commissioning, reporting and reviewing of research relating to the harmful effects of tobacco. The tobacco industry clearly values profits and expanding markets before human health, ${ }^{2}$ and is thus uniquely culpable judged by any reasonable ethical framework.

Internal documents demonstrate the extent of the tobacco industry's efforts to influence tobacco related research. Papers from the Brown and Williamson Tobacco Corporation (a subsidiary of British American Tobacco) show how the corporation concealed or distorted evidence from its own research showing the addictive and harmful nature of smoking, and stirred up unwarranted controversy about whether tobacco was harmful and addictive. ${ }^{3}$ The tobacco giant Philip Morris, through the "Whitecoat Project", tried to create controversy about the effects of passive smoking on health, and counter the findings of original research, official reports and systematic review articles. ${ }^{4}$ This project established a network of tobacco industry funded scientific "consultants" whose activities included: writing letters critical of passive smoking research; publishing review articles about the health effects of environmental tobacco smoke; establishing a "learned society" on indoor air quality; and performing diversionary ("smokescreen") research into other causes of lung cancer, such as keeping pet birds. ${ }^{4}$

The US Tobacco Institute paid $\$ 2500$ to $\$ 10000$ to authors of letters criticising the 1993 Environmental Protection Agency report that declared environmental tobacco smoke carcinogenic. ${ }^{5}$ Some letters were revised by law firms before publication. This is a subversion of the scientific purpose of academic correspondence. ${ }^{6}$ Barnes and Bero $^{7}$ found that review articles on passive smoking by authors with tobacco industry affiliations (often undeclared) were 88 times more likely to report negative findings between passive smoking and health effects than articles by scientists without tobacco industry links.

It is time for the scientific community to debate and agree on the actions needed to preserve its integrity. For example, should researchers working on diseases caused by tobacco accept tobacco funding? If so should their institutions, ethics committees and journals have special procedures to guard against bias (conscious or unconscious) in conducting and reporting research? Should declaration of conflicts of interests by tobacco industry funded researchers be compulsory, and if so is that sufficient protection against biased research? Should such declarations be only for original research, or also for reviews and academic correspondence? What action should be taken against researchers who do not declare funding from the tobacco industry? Should ethics committees have special procedures for judging research proposals sponsored by the tobacco industry? Should journal editors have special procedures for reviewing research funded by the tobacco industry? Is it right for journals to refuse to publish tobacco company sponsored research, as some have done? ${ }^{8}$

Generating consensus on how these questions should be answered is difficult, for example, how the scientific community should respond to conflicts of interest is much debated. Authors and journals disagree about whether disclosure of potential or actual conflicts of interest is necessary. ${ }^{9-13}$ About a quarter of North American journal editors required disclosure of sources of funding and institutional affiliations. ${ }^{14}$ Those arguing against the need for disclosure believe that it is a simplistic and ineffective method of guarding against biased research, and in some circumstances may result in unwarranted prejudice against researchers and suppression of scientific dialogue. ${ }^{12}{ }^{13}$ They argue that we should judge scientific publications solely on their scientific merit, and rely on the peer review process and the integrity of researchers to guard against fraud and bias. ${ }^{13}$ Tobacco industry representatives have argued similarly. ${ }^{15}$ We propose that given the evidence of the tobacco industry's influence on research into the hazardous effects and addictive nature of tobacco, the requirement for disclosure of conflicts of interest relating to the tobacco industry is essential to maintain confidence in the research process.

Long term solutions to the problem lie in the development of, and adherence to, appropriate ethical codes, and perhaps through promulgation of professional virtues like honesty, integrity, and fidelity to trust. ${ }^{16}$ Ethical guidelines for epidemiological research have included broad statements about the duties of epidemiologists to be honest and impartial, not to distort the truth, and of their moral obligation to uphold the public interest rather than narrow sectional interests. ${ }^{17}$ Other guidelines have given more specific guidance-including that epidemiologists should not accept contractual obligations contingent on reaching particular conclusions from research proposals; or accept grants or contracts in which the funder retains the right to edit or suppress results. ${ }^{18}$

In 1998, the International Epidemiology Association's European Group circulated a code of practice for epidemiologists. This has been published on the world wide web ${ }^{19}$ and states that epidemiologists should:

- "seek the truth in good faith without doing harm or jeopardising personal integrity"

- judge their own work and ideas and those of colleagues in an impartial manner

- disclose conflicts of interest to ethical review committees

- publicly acknowledge all research sponsorship

- publish all research with scientific merit

- refuse requests to withhold findings, change or tone down the content of reports, or delay publication unreasonably 
- ensure sponsors agree in writing that results will be published regardless of outcome and to the independence of the investigators

- declare sources of funding and possible conflicts of interests in publications

The IEA guidelines are extremely welcome. However, they do not solve all the ethical dilemmas that the tobacco industry's tactics raise. In particular, how do we ensure that codes of practice are disseminated and applied, and that appropriate measures are taken against researchers who fail to comply?

The scientific community needs to generate solutions. We propose the following additional measures for discussion: registers of scientists with tobacco related interests to be maintained; failure to declare tobacco related interests to be identified from the registers and noted on the published paper; publication of the identity of authors exposed as covertly funded by the tobacco industry; particularly careful scrutiny by editors and referees of the methods and conclusions drawn in tobacco industry funded research papers and refusal of publication where partiality is suspected; and educational programmes for biomedical researchers to include ethical principles in conduct of research in relation to potential conflicts of interest.

Rosemary Tong has characterised a moral dilemma as a perplexing situation in which "we cannot know what we ought to do, but nevertheless we must decide what we ought to do". ${ }^{20}$ Experience suggests that the moral dilemmas posed by the tobacco industry will persist, as it continues to use its immense resources to undermine research demonstrating the scale and urgency of the public health problem caused by tobacco, and the need for rigorous tobacco control measures. As these actions threaten the credibility of the health research endeavour, the biomedical research community must debate the problems outlined here and generate and implement solutions. This is a call to arms!

This editorial is a fuller exposition of our arguments as stated in a letter to the British Medical fournal published in February $1999 .^{21}$
RICHARD EDWARDS

RAJ BHOPAL

Department of Epidemiology and Public Health, School of Health

Sciences, The Medical School, University of Newcastle upon Tyne, NE2 $4 \mathrm{HH}$

Source of funding: none.

Conflicts of interest: Richard Edwards is (unpaid) Chair of Northern Action on Smoking and Health. Raj Bhopal is a non-executive director of the Health Education Authority.

1 The Scientific Committee on Tobacco and Health. Report of the Scientific Committee on Tobacco and Health. London: The Stationery Office, 1998.

2 Hilts PJ. Smokescreen: the truth behind the tobacco industry cover-up. Massachusetts: Addison-Wesley Publishing, 1996.

3 Todd JS, Rennie D, McAfee RE, et al. The Brown and Williamson Todd JS, Rennie D, McAfee RE, et al. The Brown and
documents: where do we go from here? $\mathscr{F A M A} 1995 ; 274: 256-8$.

4 Action on Smoking and Health UK. Philip Morris Scandal documents show how Philip Morris and its lawyers, Covington and Burling invented and orchestrated controversy around passive smoking by infiltrating highly respected science and policy institution and by buying up scientists. Available from: URL: http://www.ash.org.uk/

5 Wadman M. Dilemmas for journals over tobacco cash. Nature 1998;394: 609.

6 Bhopal RS, Tonks A. The role of letters in reviewing research. BMf 1994;308:1582-3.

7 Barnes DE, Bero LA. Why review articles on the health effects of passive smoking reach different conclusions. FAMA 1998;279:1566-70.

8 Rutter T. US journals veto tobacco funded research. BMF 1996;312:11.

9 International Committee of Medical Journal Editors. Uniform requirements for manuscripts submitted to biomedical journals. fAMA 1997;277:92734.

10 Smith R. Beyond conflict of interest: transparency is the key. $B M F$ 1998;317:291-2.

11 Krimsky S, Rothenberg LS. Financial interest and its disclosure in scientific publications. fAMA 1998;280:225-6.

12 Horton R. Conflicts of interest in clinical research: opprobrium or obsession? Lancet 1997:349:1112-13.

13 Rothman KJ. The ethics of research sponsorship. f Clin Epidemiol 1991;44 (suppl 1):25-8S.

14 Wilkes MS, Kravitz RL. Policies, practices and attitudes of North American medical journal editors. F Gen Intern Med 1995;10:443-50.

15 Proctor C. Tobacco industry research: collaboration not confrontation, is the best response. BMF 1998;317:333-4.

16 Weed DL, McKeown RE. Epidemiology and virtue ethics. Int $\mathcal{f}$ Epidemiol 1998;27:343-9.

17 Last JM. Guidelines on ethics for epidemiologists. Int f Epidemiol 1990;19: 226-9.

18 Beauchamp TL, Cook RR, Fayeweather WE, et al. Ethical guidelines for epidemiologists. F Clin Epidemiol 1991;44 (suppl 1):151-69S.

19 The IEA European Epidemiology Group. Good epidemiology practice. Proper The IEA European Epidemiology Group. Good epidemiology practice. Proper
conduct in epidemiological research. Available from: URL:http:// conduct in epidemiol

20 Tong R. The promises and perils of pragmatism: commentary on Fins, Bacchetta and Miller. Kennedy Institute of Ethics fournal 1997;7:147-52.

21 Edwards R, Bhopal R. Biomedical journals need a concerted response against influence of the tobacco industry. BMF 1999;318:465-6. 